\title{
USPOREDBA 3D TEHNIKE I DIGITALNE SUBTRAKCIJSKE ANGIOGRAFIJE U DETEKCIJI INTRAKRANIJALNIH ANEURIZMI I NJIHOVE LOKALIZACIJE
}

\author{
Darjan Franjić, Josip Mašković \\ Odjel za radiologiju, Sveučilišna klinička bolnica Mostar, 88000 Mostar,Bosna i Hercegovina \\ Fakultet zdravstvenih studija, Sveučilište u Mostaru, 88000 Mostar, Bosna i Hercegovina \\ Rad je primljen 28.2.2018. Rad je recenziran 21.3.2018. Rad je prihvaćen 29.4.2018.
}

\section{SAŽETAK}

UVOD: Zbog visoke prostorne rezolucije i visokog slikovnog kontrasta u prikazu vaskularnih struktura mozga digitalna subtrakcijska angiografija (DSA) se smatra standardnom metodom prikaza morfoloških promjena u bolesnika sa intrakranijalnim aneurizmama. Razvojem računalnog softvera razvila se 3D digitalna subtrakcijska angiografija (3DSA) koja je uklonila nedostatke 2D DSA. Usporediti 3D DSA i DSA u detekciji intrakranijalnih aneurizmi na Odjelu za radiologiju Sveučilišne kliničke bolnice (SKB) Mostar.

METODE: U ovom istraživanju provedena je retrospektivna analiza 50 bolesnika u kojih je u evaluaciji intrakranijalnih aneurizmi urađen pregled konvencionalnom DSA i 3D DSA-om.

REZULTATI: Od ukupnog broja ispitanika koji je uključen u istraživanje u pet bolesnika aneurizma nije otkrivena. Ukupno je otkriveno 60 aneurizmi. 3D DSA metodom otkrivene su 54 aneurizme. Pomoću DSA otkriveno je ukupno 37 aneurizmi. Najčešća lokalizacija aneurizmi koje su otkrivene pomoću konvencionalne DSA bila je na prednjoj komunikantnoj arteriji. Od aneurizmi prikazanih na 3D DSA najčěšća lokalizacija je bila na prednjoj cerebralnoj arteriji.

ZAKLJUČAK: U detekciji moždanih aneurizmi 3D DSA bolja je od konvencionalne DSA. Međutim, razlika između ove dvije pretrage u broju otkrivenih aneurizmi nije bila statistički značajna. U otkrivanju lokalizacije aneurizmi 3D DSA pokazala se uspješnijom u odnosu na konvencionalnu DSA na umjerenoj razini statističke značajnosti.

Ključne riječi: detekcija, lokalizacija, usporedba, intrakranijalna aneurizma

Osoba za razmjenu informacija:

mr. Darjan Franjić; email: darjanfranjic@gmail.com

\section{UVOD}

Intrakranijalne aneurizme su lokalna proširenja moždanih arterija, uzrokovane strukturalnim promjenama arterijske stjenke i hemodinamskim čimbenicima (1). Prema obliku intrakranijalne aneurizme dijelimo na: vrećaste (sakularne), aterosklerotične (fuziformne), gigantske i disecirajuće aneurizme (2). Etiološki sakularne aneurizme najčešće su posljedica kongenitalnih čimbenika i/ili degenerativnih promjena. Aterosklerotske ili fuziformne aneurizme najčešće su posljedica degenerativnih promjena medije. Disekantne aneurizme najčešće su posljedica traume (3).
Nerupturirane intrakranijalne aneurizme uključuju aneurizme otkrivene kao slučajni nalaz i aneurizme s pratećom simptomatologijom bez znakova krvarenja kao što je to na primjer proširenje zjenice zbog pareze trećeg moždanog živca (4).

Multiple aneurizme najčešće se javljaju na unutarnjoj karotidnoj arteriji te na srednjoj moždanoj arteriji. Incidencija multiplih aneurizmi ovisi o metodi pretraživanja, angiografiji i/ili autopsiji (5).

Aneurizme mogu bez izuzetaka nastati na svakoj intrakranijalnoj arteriji. Sakularne aneurizme se obično lokaliziraju na bifurkacijama arterija 
Willis-ovog arterijskog prstena na bazi mozga. Učestalije su na arterijama prednje cirkulacije mozga ili karotidnog sliva (6-9). U kliničkoj slici promjene koje se događaju neposredno nakon krvarenja karakterizira nagla pojava glavobolje, koja je najčešće vrlo intenzivna, zatim vrtoglavice, mučnine i povraćanja (simptomi povišenog intrakranijalnog tlaka) (10).

Aneurizme se mogu liječiti endovaskularnim ili kirurškim tehnikama (11). Čimbenici koji su povoljniji za kirurško liječenje u odnosu na endovaskularno liječenje su: mlađa životna dob, aneurizma srednje moždane arterije, gigantske aneurizme promjera većeg od $20 \mathrm{~mm}$, male aneurizme promjera manjeg od $2 \mathrm{~mm}$, nerupturirane aneurizme koje imaju kompresivni učinak na kranijalne živce, aneurizme širokog vrata te one s rezidualnim punjenjem nakon endovaskularnog zahvata (12).

U određivanju geometrijskih značajki intrakranijalnih aneurizma najčešće se koriste: angiografija računalnom tomografijom (MSCTA, od engl. multislice computed tomography angiography), angiografija magnetnom rezonancijom (MRA, od engl. magnetic resonance angiography), digitalna subtrakcijska angiografija (DSA, od engl. digital subtraction angiography), 3D digitalna subtrakcijska angiografija (3D DSA, od engl. 3D digital subtraction angiography) (13). Podaci o aneurizmi koji se moraju utvrditi prije operacijskog ili endovaskularnog liječenja mogu se dobiti MSCT angiografijom i MR angiografijom, međutim, u usporedbi sa DSA, ove dijagnostičke metode imaju slabiju prostornu rezoluciju i manju osjetljivost za male (< $3 \mathrm{~mm}$ ) aneurizme (14-19).

DSA je kompjuterizirana metoda vizualizacije krvnih žila primjenom jodnog kontrastnog sredstva. Kombinacijom kontrasta i denziteta poboljšanog subtrakcijom omogućava se prikaz malenih krvnih žila. Prednost DSA pred konvencionalnom angiografijom je upotreba manje količine kontrastnog sredstva. Snimanje je moguće u raznim projekcijama kao i zumiranje detalja.

Osnovni princip cerebralne angiografije je selektivna kateterizacija obje unutarnje karotidne arterije i obje vertebralne arterije $(20,21)$. Činjenica da je angiografija invazivna pretraga za čije izvođenje je potrebna punkcija pristupne periferne arterije sa svim mogućim komplikacijama koje mogu uslijediti, kao što su to hematom na mjestu punkcije, pseudoaneurizme i disekcije, predstavlja glavni nedostatak ove pretrage (22). Zbog krvnih žila koje se međusobno superponiraju, 2D DSA tehnikom teško je odrediti postojanje aneurizmi (23). Razvojem računalnog softvera, koji je novim programskim aplikacijama omogućio poslije procesorsku obradu dobivenih podataka, razvila se 3D DSA koja je uklonila nedostatke 2D DSA. Ovaj tehnološki napredak doveo je do bolje vizualizacije vaskularnog stabla čime je napravljen napredak u smanjenju slikovnih artefakata i postavljanju dijagnoze (24). Za 3D rekonstrukciju DSA slike potrebno je imati angiografski sustav sa ravnim detektorima (flat - panel) i motoriziranim rotirajućim C - lukom. Kompletna akvizicija sastoji se od dva rotacijska skeniranja (25). Rekonstrukcijom podataka 3D DSA omogućava pregled vaskularnog stabla u bilo kojoj projekciji. Najčešće poslije procesorske metode slikovnog prikaza koje se koriste pri 3D DSA su MIP (od engl. maximum intensity projection) i SSD (od engl. surface shaded display) (26-30).

\section{CILJ ISTRAŽIVANJA}

Cilj ovog istraživanja bio je utvrditi vrijednost 3D DSA u otkrivanju intrakranijalnih aneurizmi usporedbom učinkovitost 3D DSA i konvencionalne DSA u otkrivanju intrakranijalnih aneurizmi. Dodatni cilj ovog istraživanja bio je utvrditi da li na osnovu podataka dobivenih 3D DSA metodom i konvencionalnom DSA ima razlike u detekciji intrakranijalnih aneurizmi s obzirom na lokalizaciju, oblik i njihov odnos sa okolnim arterijama.

\section{ISPITANICI I METODE}

$\mathrm{U}$ ovom istraživanju provedena je retrospektivna analiza 50 bolesnika u kojih je u detekciji intrakranijalnih aneurizmi urađen pregled konvencionalnom DSA i 3D DSA-om. Analizirani su podaci Sveučilišne kliničke bolnice u Mostaru - Zavod za radiologiju koji su prikupljani između rujna 2016. godine i srpnja 2017. godine. Podaci su prikupljeni iz baze 
podataka radne stanice na kojoj se nalaze DSA i 3D DSA prikazi. Za prikupljanje slikovnih prikaza korišten je kompaktni disk. Dobivene 2D, 3D, MIP i SSD dijagnostičke slike su bile nasumično raspoređene. Određivanje prisutnosti i položaja aneurizme na tim slikovnim prikazima uradio je specijalist radiolog. Kvaliteta slika koje su dobivene jednom i drugom metodom uspoređena je na četverostupanjskoj ljestvici: 1. nalaz nije dovoljno jasan za dijagnozu; 2 . nalaz ukazuje na moguće postojanje aneurizme ali nedovoljno za dijagnozu; 3. nalaz je dovoljno dobar za detekciju aneurizme, ali vizualizacija cerebralnih arterija nije jasno vidljiva; 4 . nalaz je izvrstan za dijagnozu postojanja aneurizme i vizualizacija cerebralnih arterija je jasna. Također je izvršeno ocjenjivanje prisutnosti aneurizme na sljedećoj skali: 1. odsutna; 2. vjerojatno odsutna; 3 . neizvjesno; 4 . vjerojatno prisutna; 5. prisutna. Etičko odobrenje dobili smo od ustanove u kojoj je provedeno istraživanje. U obzir smo u svrhu istraživanja uzimali samo parametre vezane za dijagnostičke slike, spol i godinu rođenja pacijenta.

U istraživanje su uključeni samo bolesnici kod kojih je napravljena konvencionalna DSA i 3D DSA sa sumnjom na postojanje suspektnih aneurizmi. Iz istraživanja su isključeni oni bolesnici na kojima je dokazana prisutnost „lažnih“ aneurizmi nakon obavljenih pretraga DSA i 3D DSA metodama. Dob bolesnika ispitivane grupe bila je između 28 . i 81 . godine. Aritmetička sredina za dob bolesnika ispitivane grupe iznosi 50,61. Prosječno odstupanje od prosječne dobi bolesnika ispitivane grupe iznosi 12,13. Varijabilitet dobi je $22 \%$.

Za usporedbu kvalitete prikaza intrakranijalnih aneurizmi na konvencionalnoj DSA i 3D DSA analizirali smo broj otkrivenih aneurizmi, vidljivost vrata, njihovu veličinu i lokalizaciju.

Usporedba broja otkrivenih aneurizmi rađena je na osnovi broja aneurizmi vidljivih na slikovnom prikazu konvencionalne DSA i 3D DSA.

U svakog bolesnika u kojeg je otkrivena intrakranijalna aneurizma njena veličina mjerena je u milimetrima. $\mathrm{Za}$ analizu veličine otkrivene aneurizme na konvencionalnoj i 3D DSA korištena je ista radna stanica.
Usporedba lokalizacije rađena je na način da se vidljiva lokalizacija označavala nazivom arterije na kojoj se aneurizma nalazila, a znakom 0 ukoliko aneurizma na jednoj od pretraga nije bila vidljiva.

\section{Statističke metode obrade podataka}

Prikupljeni podaci, nakon njihove logičke obrade su uneseni u bazu podataka MS Excel 2013, a za statističku analizu koristio se statistički program SPSS 18 (SPSS for Windows 18.0,SPSS, Chicago, IL,SAD ). Vizualno/logičko strukturiranje podataka odnosi se na upotrebu raznih funkcionalnosti DATA opcija u MS Excel programu.

U obradi podataka koristile su se metode deskriptivne statistike. Podaci su prikazani kao frekvencija i postotak za kategorijske varijable, medijan i raspon za ordinalne, te kao srednja vrijednost i standardna devijacija za kontinuirane varijable. Mod je korišten za određivanje srednje vrijednosti za kontinuirane varijable u ovom istraživanju jer postoje najmanje dvije jednake vrijednosti varijable.

Standardna devijacija je određivana na način da je u Microsoft Excel tablicu unošena formula za određivanje standardne devijacije $\mathrm{u}$ ovom progra$\mathrm{mu}$ (=SDEVP), te je potom u zagradu unošen zbroj, odnosno aritmetička sredina dobivenih brojčanih podataka.

Za testiranje statističke značajnosti razlika numeričkih varijabli, vezanih za analizirane parametre različitih dijagnostičkih tehnika primijenjen je Studentov-t test.

Za mjerenje podudarnosti u lokalizaciji intrakranijalnih aneurizmi između dviju metoda korišten je Cohen kappa-ov koeficijent (k). Ukoliko je k-vrijednost veća od 0 podudarnost je pozitivna; ako je manja od 0,4 i dalje je pozitivna ali je slaba; $0,41-0,75$ - umjerena razina podudarnosti; veća od 0,75 - podudarnost je odlična. Razina vjerojatnosti od $\mathrm{p}<0,05$ uzeta je kao statistički značajna.

Nominalne i ordinalne varijable uspoređene su hi-kvadrat testom, a pri manjku očekivane frekvencije korišten je Fisherov egzaktni test.

\section{REZULTATI}

U ovom istraživanju 3D DSA je prikazala ukupno 54 intrakranijalne aneurizme, dok je na DSA 
slici prikazano ukupno 37 aneurizmi. Mada je sa 3D DSA dokazan veći broj aneurizmi nego li s konvencionalnom DSA ne postoji značajna statistička razlika $(\chi 2=3,176 ; \mathrm{df}=1 ; \mathrm{p}=0,074)$ (Tablica 1.).

Tablica 1. Prikaz broja otkrivenih aneurizmi DSA i 3D DSA metodom

\begin{tabular}{|c|c|c|}
\hline Naziv metode & Broj aneurizmi & Postotak \\
\hline DSA & 37 & $61,66 \%$ \\
\hline 3D DSA & 54 & $90 \%$ \\
\hline Broj prikazanih aneurizmi & 60 & $100 \%$ \\
\hline
\end{tabular}

Na Slici 1. prikazane su najveće razlike u uspješnosti dijagnostike lokalizacije aneurizme na konvencionalnoj DSA i 3D rotacijskoj DSA. Razlika između ove dvije metode u lokalizaciji aneurizmi je na razini statističke značajnosti $(\chi 2=14,837 ; \mathrm{df}=5$; $\mathrm{p}=0,011)$. Razlika se očituje u prikazu aneurizmi na prednjoj moždanoj arteriji gdje je 3D DSA metoda bila uspješnija u detekciji intrakranijalnih aneurizmi kao i udetekciji višestruke lokalizacije. Međusobni omjer između 3D DSA i DSA u prikazu intrakranijalnih aneurizmi na prednjoj moždanoj arteriji prema izračunu baznog indeksa iznosi 2,5 ( $\mathrm{I}=2,5)$. Bazni indeks u otkrivanju višestruke lokalizacije između ove dvije metode je 10.

Razlika između 3D DSA i DSA se očituje i na prednjoj komunikantnoj arteriji. DSA je na toj arteriji detektirala više aneurizmi od 3D DSA. Međusobni omjer između 3D DSA i DSA u prikazu intrakranijalnih aneurizmi na komunikantnoj arteriji prema izračunu baznog indeksa je 3 .

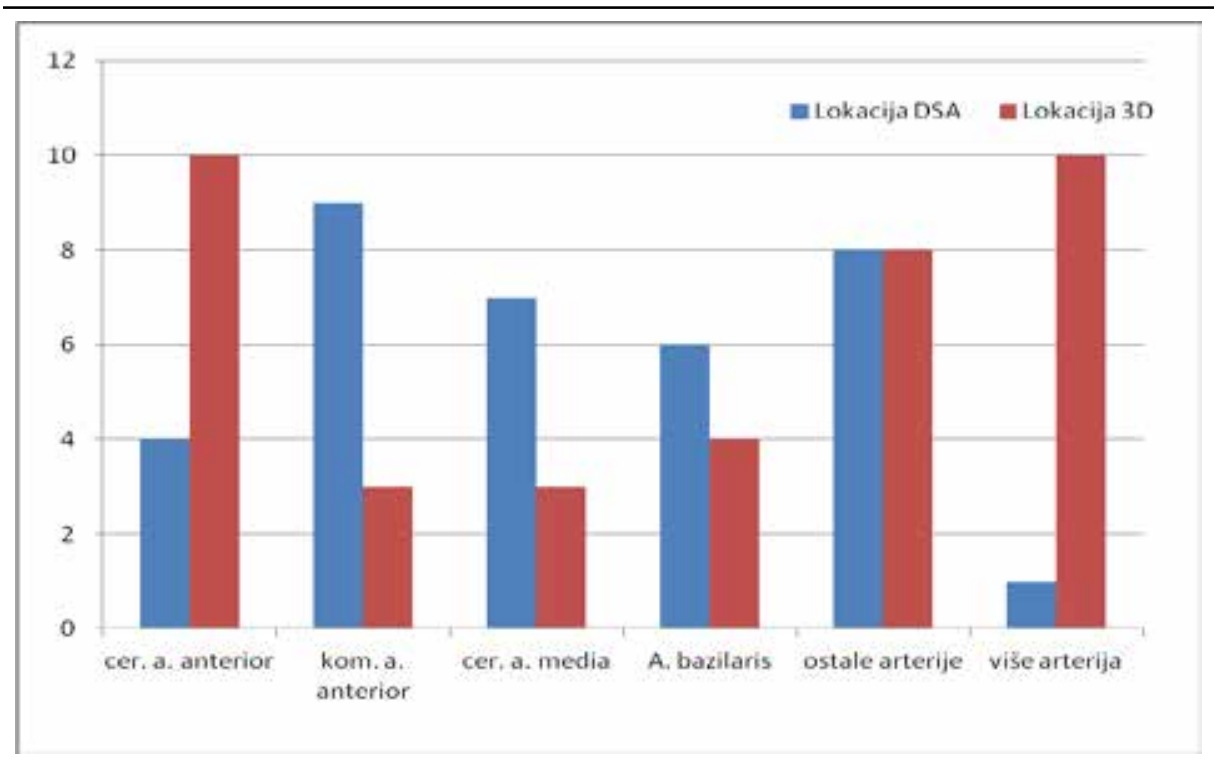

Slika 1. Razlike u lokalizaciji aneurizmi pri konvencionalnoj DSA i 3D rotacijskoj angiografiji

Najveći postotak aneurizmi konvencionalnom DSA detektiran je na prednjoj komunikantnoj arteriji (Tablica 2.).

Tablica 2. Prikaz lokalizacije aneurizmi konvencionalnom DSA

\begin{tabular}{|c|c|c|}
\hline \multicolumn{3}{|c|}{ KONVENCIONALNA DSA } \\
\hline Naziv arterija & Broj bolesnika & Postotak \\
\hline Prednja komunikantna arterija & 9 & $25,714 \%$ \\
\hline Srednja moždana arterija & 7 & $20 \%$ \\
\hline Bazilarna arterija & 6 & $17,142 \%$ \\
\hline Prednja moždana arterija & 4 & $11,428 \%$ \\
\hline Višestruka lokalizacija & 1 & $2,857 \%$ \\
\hline Ostale arterije & 8 & $22,857 \%$ \\
\hline Broj bolesnika u kojih je otkrivena aneurizma & 35 & $100 \%$ \\
\hline
\end{tabular}

Na Slici 2a. možemo vidjeti da DSA prikazuje aneurizmu na srednjoj moždanoj arteriji te suspektnu aneurizmu na stražnjoj komunikantnoj arteriji. $\mathrm{Na}$ 3D SSD rekonstrukciji prikazuju se tri aneurizme koje su lokalizirane na srednjoj moždanoj arteriji i stražnjoj komunikantnoj arteriji. Ovom metodom intrakranijalna aneurizma je prikazana i na prednjoj moždanoj arteriji (Slika 2b.). 


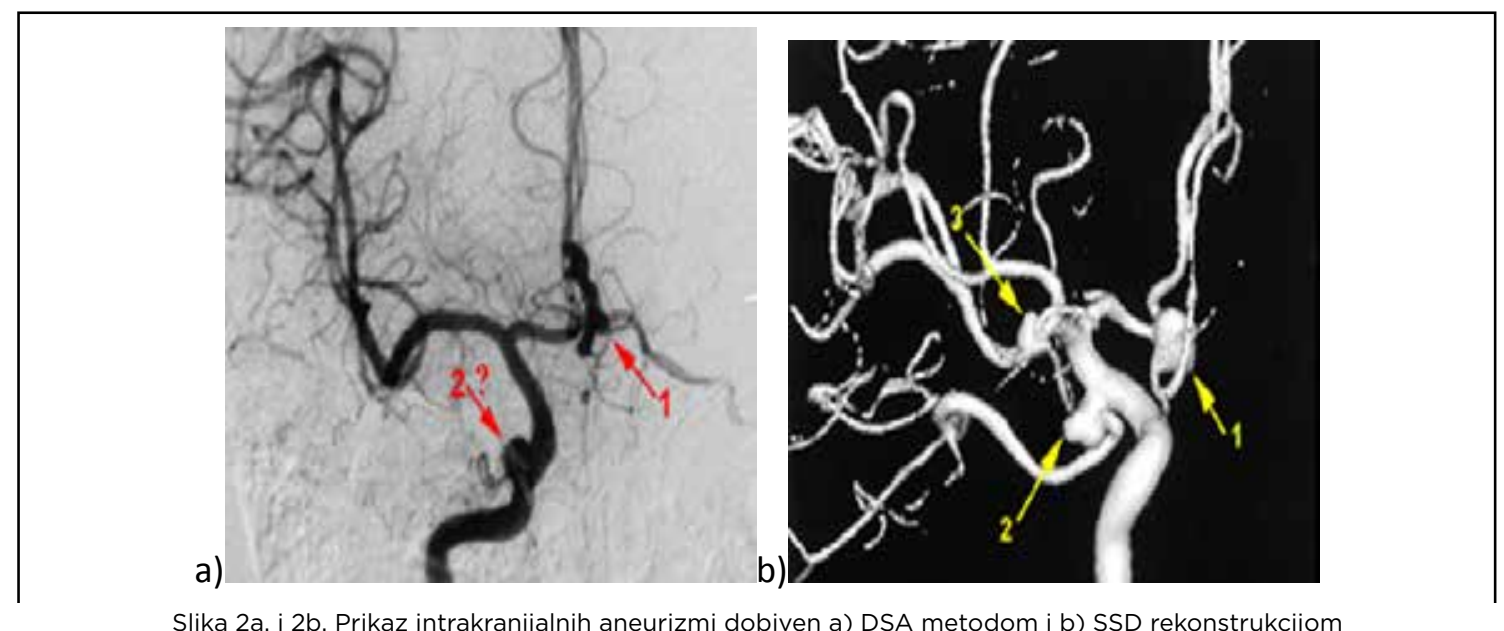

U Tablici 3. vidljivo je da je 3D DSA bila najuspješnija u prikazu intrakranijalnih aneurizmi na prednjoj moždanoj arteriji.

Tablica 3. Prikaz lokalizacije aneurizmi 3D DSA me-

todom

\begin{tabular}{|l|c|c|}
\hline \multicolumn{3}{|c|}{ 3D DSA } \\
\hline Naziv arterije & Broj bolesnika & Postotak \\
\hline Prednja komunikantna arterija & 3 & $7,894 \%$ \\
\hline Srednja moždana arterija & 3 & $7,894 \%$ \\
\hline Bazilarna arterija & 4 & $10,526 \%$ \\
\hline Prednja moždana arterija & 10 & $26,315 \%$ \\
\hline Višestruka lokalizacija & 10 & $26,315 \%$ \\
\hline Ostale arterije & 8 & $21,052 \%$ \\
\hline Broj bolesnika kod kojijh je otkrivena aneurizma & 38 & $100 \%$ \\
\hline
\end{tabular}

Na Slici 3a vidi se DSA prikaz jedne aneurizme na prednjoj moždanoj arteriji, dok se na Slici $3 b$ vidi 3D DSA prikaz dvije aneurizme na istoj arteriji (označene strelicama).

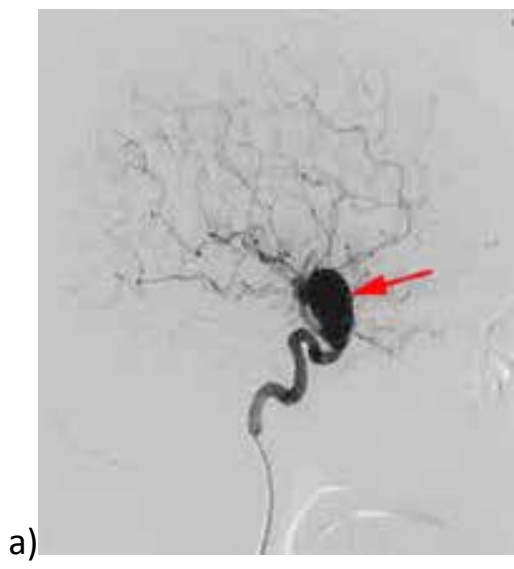

b)



Slika 3a i 3b: Prikazi intrakranijalnih aneurizmi dobiveni DSA i 3D DSA metodom. 
U Tablici 4. vidi se kako je nađena podudarnost između dviju metoda u lokalizaciji otkrivenih aneurizmi na razini statističke značajnosti. Podudarnost između metoda je bila na umjerenoj razini što nam pokazuje Cohen kappa-ov koeficijent $(\mathrm{k}=0,586)$.

Tablica 4. Mjera podudarnosti u lokalizaciji otkrivenih aneurizma između korištenih metoda

\begin{tabular}{|c|c|c|c|c|c|c|c|c|c|}
\hline & \multicolumn{6}{|c|}{ Lokaciia aneurizme 3D } & \multirow[b]{2}{*}{ K } & \multirow{2}{*}{$P$} \\
\hline & & $\mathrm{PMA}^{* *}$ & $\mathrm{PKA}^{\prime}$ & SMA" & $B A^{*}$ & Ostale & $\mathrm{VL}^{*}$ & & \\
\hline \multirow[b]{2}{*}{ Lokacija } & PMA & 4 & 0 & 0 & 0 & 0 & 0 & \multirow[t]{6}{*}{0,586} & \multirow[t]{6}{*}{$<0,001$} \\
\hline & PKA & 1 & 2 & 0 & 0 & 0 & 4 & & \\
\hline \multirow{2}{*}{ aneurizme } & SMA & 0 & 0 & 2 & 0 & 0 & 4 & & \\
\hline & $B A$ & 0 & 0 & 0 & 3 & 0 & 0 & & \\
\hline \multirow[t]{2}{*}{ DSA } & Ostale & 0 & 0 & 0 & 0 & 6 & 1 & & \\
\hline & & 0 & 0 & 0 & 0 & 0 & & & \\
\hline
\end{tabular}

Višsestruka lokalizacija; **Prednja moždana arterija, Prednja komunikantna arterija,

Srednja moždana arterija, *Bazilarna arterija

\section{RASPRAVA}

U rezultatima ovog istraživanja postoji sistematska razlika u detekciji intrakranijalnih aneurizmi između konvencionalne DSA i 3D DSA. U detekciji intrakranijalnih aneurizmi prema rezultatima našeg ispitivanja 3D DSA u odnosu na konvencionalnu DSA pokazala se uspješnijom. Razlika u broju otkrivenih aneurizmi između konvencionalne DSA i 3D DSA jedan je od parametara koji smo koristili za usporedbu ove dvije metode. Naši rezultati pokazuju da je 3D DSA otkrila 17 aneurizmi više od konvencionalne DSA.

Wongovi rezultati istraživanja pokazuju da je $3 \mathrm{D}$ DSA otkrila 44 aneurizme u 31 bolesnika, dok aneurizma nije otkrivena u četiri bolesnika. Konvencionalna DSA je prikazala 41 aneurizmu (31). Poput naših rezultata i u Wongovom istraživanju nije zabilježena statistički značajna razlika između konvencionalne DSA i 3D DSA u broju otkrivenih aneurizmi. Naši rezultati pokazuju da su u šest bolesnika $3 \mathrm{D}$ rotacijskom angiografijom bile prikazane dvije aneurizme, dok je kod istih bolesnika na konvencionalnoj DSA prikazana jedna aneurizma.

Lokalizacija aneurizme predstavlja sljedeći parametar koji smo koristili za usporedbu konvencionalne DSA i 3D DSA. U našem istraživanju najčešća lokalizacija aneurizmi koje su otkrivene pomoću konvencionalne DSA i 3D DSA bila je na prednjoj komunikantnoj arteriji i prednjoj moždanoj arteriji.
U Sugaharovoj analizi najčešća lokalizacija aneurizmi bila je na prednjoj moždanoj arteriji $(\mathrm{n}=11)$, dok je 10 aneurizmi bilo lokalizirano na stražnjoj komunikantnoj arteriji (32). Razlika između našeg i Sugaharinog istraživanja je u veličini uzorka. On je u svojoj analizi koristio manje bolesnika, njih 36 . Metode koje su korištene podudaraju se $s$ našim metodama. I on je također koristio MIP i SSD tehnike za analizu 3D DSA prikaza. Njegovi rezultati također pokazuju da je 3D DSA bila uspješnija u detekciji intrakranijalnih aneurizmi od DSA, naročito SSD tehnika što se također podudara s našim rezultatima.

Van Rooij u svojim rezultatima navodi da od ukupno 94 otkrivenih aneurizmi njih 27 nije prikazano na DSA slici, dok su iste na 3D DSA slici prikazane. Također, u njegovim rezultatima je navedeno da se lokalizacija neprikazanih aneurizmi nije razlikovala od lokalizacija aneurizmi koje su prikazane i jednom i drugom metodom (33). Rezultati našeg istraživanja se podudaraju s Van Rooij-ovim u detekciji intrakranijalnih aneurizmi, jer je i u našem istraživanju 3D DSA bila uspješnija u detekciji aneurizmi. Međutim, u lokalizaciji aneurizmi rezultati našeg istraživanja se ne podudaraju s Van Rooij-ovim rezultatima jer je lokalizacija aneurizme utjecala na njihov prikaz kako 3D DSA tako i DSA metodom. Razlika između našeg i Van Rooij-ovog istraživanja je također i u veličini uzorka. $U$ njegovom istraživanju uključeno je 350 ispitanika.

U Kawashima-inoj analizi 69 bolesnika, u kojoj je uspoređivana DSA i 3D DSA u detekciji, 3D DSA se pokazala uspješnijom. 3D tehnika za prikazivanje volumena ( VR, od engl. volume rendering) imala je kod 15 bolesnika tendenciju prikaza veće aneurizme od aneurizme prikazane na DSA slici, naročito na području prednje moždane arterije (34). U našem istraživanju korištenjem ove tehnike to se nije pokazalo. Lokalizacija aneurizme u našem istraživanju nije utjecala na prikaz njene veličine.

U istraživanju koje je proveo Shi rezultati su pokazali da je 3D DSA uspješnija u detekciji intrakranijalnih aneurizmi, naročito u detekciji aneurizmi koje su promjera manjeg od $3 \mathrm{~mm}$. Najviše aneurizmi je otkriveno na unutarnjoj karotidnoj arteriji 
i prednjoj moždanoj arteriji (35). Ovi rezultati se podudaraju s našim rezultatima koji pokazuju da je detekcija aneurizmi 3D DSA metodom najučestalija na prednjoj moždanoj arteriji. Shi u svojoj studiji ima 138 bolesnika u kojih je urađena DSA i 3D DSA. Shi je tijekom 3D obrade podataka istovremeno koristio i VR tehniku. U našem istraživanju je naknadno korištena SSD i MIP 3D tehnika.

Anxionat je u svojoj analizi 22 rupturirane aneurizme koristio 2D DSA tehniku MIP i SSD tehnike. Njegovi rezultati pokazuju da je SSD tehnika kod svake aneurizme bila uspješna u detekciji aneurizme, analizi njenog oblika i njene lokalizacije (36). Ovi rezultati se podudaraju s našim rezultatima jer su pokazali da je SSD tehnika otkrila najviše aneurizmi na onim mjestima gdje ostale metode aneurizmu nisu detektirale.

Hirai je proveo prospektivnu studiju u kojoj je istraživana vrijednost 3D DSA u detekciji intrakranijalnih aneurizmi $\mathrm{u}$ odnosu na konvencionalnu DSA (37). U istraživanje je bilo uključeno 23 bolesnika u kojih je otkriveno 30 aneurizmi. Njegovi rezultati pokazuju da je 3D tehnika (SSD, MIP i VR) u 25 aneurizmi detektirala njihovu lokalizaciju i povezanost $\mathrm{s}$ okolnim arterijama. Postotak detektiranih intrakranijalnih aneurizmi pomoću 3D DSA podudara se $s$ rezultatima našeg istraživanja. Međutim, $u$ našem istraživanju korišten je veći broj bolesnika i detektirano je ukupno više aneurizmi. Metodologija istraživanja koje je proveo Hirai podudara se s metodologijom našeg istraživanja jer su korištene iste metode 3D tehnike za detekciju aneurizmi. Jedina razlika je u analizi prikaza koji su dobiveni DSA i 3D DSA metodom. U istraživanju koje je proveo Hirai analizu slika uradila su dva radiologa odvojeno, dok je u našem istraživanju analizu dobivenih slika uradio jedan radiolog.

Hochmuth je također proveo usporedbu DSA i 3D DSA u detekciji intrakranijalnih aneurizmi (38). U njegovoj studiji ukupno je otkriveno 56 aneurizmi. 3D DSA metodom detektirano je sedam aneurizmi koje nisu detektirane na DSA slici, dok jedna aneurizma nije detektirana 3D DSA metodom. Njegovi rezultati kao i naši su pokazali da je 3D DSA uspješnija u detekciji intrakranijalnih aneurizmi.
Međutim, uspoređujući naše rezultate s rezultatima koje je dobio Hochmuth možemo vidjeti da se u našem istraživanju DSA pokazala uspješnijom metodom u detekciji intrakranijalnih aneurizmi. Iako je 3D DSA otkrila ukupno više aneurizmi , u sedam bolesnika DSA je prikazala aneurizmu dok $\mathrm{u}$ istih bolesnika 3D DSA metodom aneurizma nije detektirana.

\section{ZAKLJUČCI}

Rezultati ovog istraživanja pokazuju da razlika između ove dvije pretrage u broju otkrivenih aneurizmi nije statistički značajna. U otkrivanju lokalizacije aneurizmi razlika između konvencionalne DSA i rotacijske 3D DSA je na umjerenoj razini statističke značajnosti. Razlika u lokalizaciji intrakranijalnih aneurizmi se najviše očitovala na prednjoj moždanoj arteriji, stražnjoj komunikantnoj arteriji i u višestrukoj lokalizaciji intrakranijalnih aneurizmi. Na prednjoj moždanoj arteriji uspješnija u prikazu intrakranijalnih aneurizmi se pokazala $3 \mathrm{D}$ DSA, dok se na stražnjoj komunikantnoj arteriji u prikazu intrakranijanih aneurizmi uspješnijom pokazala konvencionalna DSA. Time su rezultati ovog istraživanja pokazali da lokalizacija intrakranijalnih aneurizmi utječe na njihovu detekciju. 3D DSA se pokazala uspješnijom u prikazu više aneurizmi na istom prikazu. Rezultati istraživanja pokazuju da je DSA u detekciji intrakranijalnih aneurizmi i dalje uspješna dijagnostička metoda te da uz naknadnu obradu pomoću 3D tehnike predstavlja zlatni standard u detekciji intrakranijalnih aneurizmi.

\section{LITERATURA}

1. Horowitz M. Guidelines for the surgical treatment of unruptured intracranial aneurysms: the first annual J. Lawrence pool memorial research symposium - controversies in the managament of cerebral aneurysms. Neurosurgery 2009;64:E577.

2. Drake CG. Giant intracranial aneurysms: experience with surgical treatment in $174 \mathrm{pa}-$ tients. Clin Neurosurg. 1979;26:12-95.

3. Raabe A, Beck J, Rohde S, Berkefeld J, Seifert $\mathrm{V}$. Three-dimensional rotational angiography 
guidance for aneurysm surgery. J Neurosurg 2007(105):406-411.

4. The International Study of Unruptured Intracranial Aneurysm Investigators. Unruptured Intracranial aneurysms - risk of rupture and risks of surgical intervention. N Engl J Med $1998 ; 339: 1725-33$.

5. Ostergaard JR, $\mathrm{H} \emptyset \mathrm{g}$ E. Incidence of multiple intracranial aneurysms. J Neurosurg 1985;63:49-55.

6. Koivisto T. Cerebral perfusion before and after endovascular or surgical treatment of acutely ruptured cerebral aneurysms: a one-year prospective follow-up study. Neurosurgery 2002;51(2);312-326.

7. Qureshi AI, Janardhan V, Hanel RA, Lanzino G. Comparison of endovascular and surgical treatments forintracranial aneurysms: an evidence - based review. Lancet Neurol. 2007 Sep;6(9):816-25.

8. Kaye AH. Essential Neurosurgery. 3rd rev. ed. Stewart J. Oxford; Blackwell Publishing Ltd; 2005. p. 281.

9. Bederson JB, Connolly ES, Batjer HH, Dacey RG, Dion JE, Diringer MN et al. Guidelines for the management of aneurysmal subarachnoid hemorrhage: a statement for healthcare professionals from a special writing group of the stroke council. American Heart Association. 2009 Mar;40(3):994-1025.

10. Wheelock B, Weir B, Watis R, Mohr G, Khan $M$, Hunter $M$ et al. Timing of surgery for intracerebral hematomas due to aneurysm rupture. J Neurosurg 1983;58:476-81.

11. Cossu M, Pau A, Turtas S, Viola C, Viale GL. Subsequent bleeding from ruptured intracranial aneurysms treated by wrapping or coating: a review of the long - term results in 47 cases. Neurosurgery 1993;32:344-6.

12. Chen PR, Amin-Hanjani S, Albuquerque FC, McDougall C, Zabramski JM, Spetzler RF. Outcome of oculomotor nerve palsy from posterior communicating artery aneurysms: comparison of clipping and coiling. Neurosurgery 2006;58:1040-6.
13. Brinjikji W, Cloft H, Lanzino G, Kallmes DF. Difficult aneurysms for endovascular treatment: overwide or undertall? AJNR Am J Neuroradiol. 2009 Apr;30(4):831-4.

14. Velthuis BK, Rinkel GJE, Ramos LMP. Subarachnoid hemorrhage: aneurysm detection and preoperative evaluation with CT angiography. Radiology 1998; 208:423-430.

15. Alberico RA, Patel M, Casey S, Jacobs B, Maguire W, Decker R. Evaluation of the circle of Willis with three-dimensional CT angiography in patients with suspected intracranial aneurysms. AJNR Am J Neuroradiol 1995;16:1571-1578.

16. Schwartz RB, Tice HM, Hooten SM, Hsu LH, Stieg PE. Evaluation of intracranial aneurysms with helical CT: correlation with conventional angiography and MR angiography. Radiology 1994;192:717-722.

17. Heinz ER. Commentary: prospective evaluation of the circle of Willis with three-dimensional CT angiography in patients with suspected intracranial aneurysms. AJNR Am J Neuroradiol 1995. 1579-1580.

18. Korogi Y, Takahashi M, Katada K. Intracranial aneurysms: detection with three-dimensional CT angiography with volume rendering - comparison with conventional angiographic and surgical findings. Radiology 1999;211:497-506.

19. Ida M, Kurisu Y, Yamashita M. MR angiography of ruptured aneurysms in acute subarachnoid hemorrhage. AJNR Am J Neuroradiol 1997;18:1025-1032.

20. Wheelock B, Weir B, Watis R, Mohr G, Khan $M$, Hunter $\mathrm{M}$ et al. Timing of surgery for intracerebral hematomas due to aneurysm rupture. J Neurosurg 1983;58:476-81.

21. Maffei L, Bracard S, Bendre A, Per A, Anxionnat R, Marchal JC, Picard L. Interest of repeated cerebral angiography in subarachnoid hemorrhages. Eur Radiol 1995;5:492-4.

22. Executive committee for the asymptomatic carotid atherosclerosis study: endarterectomy 
for asymptomatic carotid artery stenosis. JAMA 1995 May 10; 273(18):1421-1428.

23. Sugahara T, Korogi Y, Nakashima K, Hamatake S, Honda S, Takahashi M. Comparison of $2 \mathrm{D}$ and $3 \mathrm{D}$ digital subtraction angiography in evaluation of intracranial aneurysms. AJNR Am J Neuroradiol 2002;23:1545-1552.

24. Anxionnat R, Bracard S, Ducrocq X. Intracranial aneurysms: clinical value of 3D digital subtraction angiography in the therapeutic decision and endovascular treatment. Radiology 2001;218:799-808.

25. Cieściński J, Serafin Z, Strześniewski P, Lasek W, Beuth W. DSA volumetric 3D reconstructions of intracranial aneurysms: a pictorial essay. Pol J Radiol 2012; 77(2): 47-53.

26. Sugahara T, Korogi Y, Nakashima K, Hamatake S, Honda S, Takahashi M. Comparison of $2 \mathrm{D}$ and $3 \mathrm{D}$ digital subtraction angiography in evaluation of intracranial aneurysms. AJNR Am J Neuroradiol 2002;23:1545-1552.

27. Anxionnat R, Bracard S, Ducrocq X, et al. Intracranial aneurysms: clinical value of $3 \mathrm{D}$ digital subtraction angiography in the therapeutic decision and endovascular treatment. Radiology 2001;218:799-808.

28. Van Rooij WJ, Sprengers ME, de Gast AN, Peluso JP, Sluzewski M.3D rotational angiography: the new gold standard in the detection of additional intracranial aneurysms. AJNR Am J Neuroradiol. 2008 May;29(5):976-9.

29. Hochmuth A, Spetzger U, Schumacher M. Comparison of three-dimensional rotational angiography with digital subtraction angiography in the assessment of ruptured cerebral aneurysms. AJNR Am J Neuroradiol 2002;23:1199-205.

30. Beck J, Rohde S, Berkefeld J, et al. Size and location of ruptured and unruptured intracranial aneurysms measured by 3-dimensional rotational angiography. Surg Neurol 2006;65:18-27.
31. Wong SC, Nawawi O, Ramli N, Abd Kadir KA. Benefits of 3D rotational DSA compared with 2D DSA in the evaluation of intracranial aneurysm. Acad Radiol 2012 Jun;19(6):701-7.

32. Sugahara T, Korogi $Y$, Nakashima K, Hamatake S, Honda S, Takahashi M. Comparison of $2 \mathrm{D}$ and $3 \mathrm{D}$ digital subtraction angiography in evaluation of intracranial aneurysms. AJNR Am J Neuroradiol 2002;23:1545-1552.

33. Van Rooij WJ, Sprengers ME, de Gast AN, Peluso JP, Sluzewski M. 3D rotational angiography: the new gold standard in the detection of additional intracranial aneurysms. AJNR Am J Neuroradiol 2008 May;29(5):976-9.

34. Kawashima M, Kitahara T, Soma K, Fujii K. Three dimesional digital subtraction angiography vs two-dimensional digital subtraction angiography for detection of ruptured intracranial aneurysms: a study of 86 aneurysms. Neurol India 2005 Sep;53(3):287-9

35. Shy WY, Li YD, Li MH, Gu BX, Chen SW, Wang $\mathrm{W}$ et al. 3D rotational angiography with volume rendering: The utility in the detection of intracranial aneurysms. Neurol India 2010 Nov-Dec;58(6):908-13.

36. Anxionnat R, Bracard S, Ducrocq X. Intracranial aneurysms: clinical value of $3 \mathrm{D}$ digital subtraction angiography in the therapeutic decision and endovascular treatment. Radiology. 2001;218:799-808.

37. Hirai T, Korogi Y, Suginohara K, Ono K, Nishi $\mathrm{T}$, Uemura $\mathrm{S}$ et al. Clinical usefulnes of unsubtracted 3D digital angiography compared with rotational digital angiography in the pretreatment evaluation of intracranial aneurysms. AJNR Am J Neuroradiol. 2003 JunJul;24(6):1067-74.

38. Hochmuth A, Spetzger U, Schumacher M. Comparison of three-dimensional rotational angiography with digital subtraction angiography in the assessment of ruptured cerebral aneurysms. AJNR Am J Neuroradiol. 2002 Aug;23(7):1199-205. 


\title{
COMPARISON OF 3D TECHNIQUE AND DIGITAL SUBTRACTION ANGIOGRAPHY IN DETECTION OF INTRACRANIAL ANEURYSMS AND THEIR LOCALIZATION
}

\author{
Darjan Franjić, Josip Mašković \\ Department of Radiology, University Clinical Hospital Mostar, Bosnia and Herzegovina \\ Faculty of Health Studies, University of Mostar, Bosnia and Herzegovina
}

\begin{abstract}
INTRODUCTION: Due to high spatial resolution and image contrast in the presentation of vascular brain structures, digital subtraction angiography (DSA) is considered a standard method of representation of morphological changes in patients with intracranial aneurysms. 3D digital subtraction that eliminated the disadvantages of 2D DSA evolved with the development of computer software.

OBJECTIVE: Compare 3D DSA and DSA in detection of intracranial aneurysms at the Department of Radiology of the University Clinical Hospital Mostar.

SUBJECTS AND METHODS: In this study, we conducted a retrospective analysis of 50 patients in the evaluation of intracranial aneurysms with conventional DSA and 3D DSA.

RESULTS: Out of the total number of subjects included in the study, aneurysms were not detected in five patients. A total of 60 aneurysms were detected. The 3D DSA method detected 54 aneurysms. The conventional DSA method detected 37 aneurysms. The most common localization of aneurysms detected by conventional DSA was on the anterior communicating artery. Aneurysms detected by 3D DSA were most commonly localized on the posterior cerebral artery.

CONCLUSION: In the detection of brain aneurysms, 3D DSA is better than conventional DSA. However, the difference between these two methods in the number of detected aneurysms is not statistically significant. 3D DSA proved to be more successful in the detection and localization of aneurysms when compared to conventional DSA at a moderate level of statistical significance.
\end{abstract}

Key words: detection, localization, comparison, intracranial aneurysm

Correspondence:

Darjan Franjić, MA

E-mail: darjanfranjic@gmail.com 